\title{
Mirar adentro, actuar desde el centro. Por la via pulchritudinis a la acción teodrámatica: una voz cristiana en el escenario de la postmodernidad
}

Cecilia Avenatti de Palumbo

A José Carlos Barcellos (In memoriam)

\section{Resumen}

La mirada y la acción desde el centro interior personal pertenecen al dinamismo del itinerario estético-dramático desarrollado por Hans Urs von Balthasar, quien considera que en este mirar radica la respuesta estética del sujeto ante la objetiva manifestación de la figura y que dicha acción se identifica con representación dramática del amor divino en la historia humana. La tesis que sostiene la autora es que esta articulación dinámica constituye el germen de lo que propone llamar el "giro estético-dramático cristiano", en el que la teodramática deviene en consumación perfomativa de lo estético, lo cual la convierte en una alternativa teológica que permitiría incluir la perspectiva cristiana en el escenario de la posmodernidad.

Palabras claves: Hans Urs von Balthasar, posmodernidad, giro estético dramático, acción performativa.

\section{Abstract}

The glance and the action from inside center staff belong to the dynamism of dramatic aesthetic itinerary developed by Hans Urs von Balthasar, who believes 
that in this look lies the subject's aesthetic response to the objective manifestation of the figure and that such action is identified dramatic representation of divine love in human history. The thesis argues the author is that this dynamic articulation is the germ of what he proposes to call the "aesthetic-dramatic turn christian ", in which the theodrama turns into performative consummation of the aesthetic. This makes it an alternative theological would include the Christian perspective on the stage of postmodernism.

Keywords: Hans Urs von Balthasar, postmodernism, aesthetic and dramatic turn, performative action.

Quien mira desde lo interior sabe que todo es nuevo.

C.G. Jung

\section{Introducción}

Mirar adentro, actuar desde el centro: dos momentos del mismo itinerario estético-dramático desarrollado por Hans Urs von Balthasar, a partir del cual postulamos la inclusión de la perspectiva cristiana en el escenario de una postmodernidad, con la que el autor comparte, al menos, el mismo espíritu del tiempo cuya nota distintiva es el quiebre de la racionalidad moderna. La mirada interior y la acción originada desde este centro personal son consideradas por Balthasar como la respuesta subjetiva a la objetiva manifestación estética de la figura y representación dramática del amor divino. Nuestra tesis es que precisamente esta articulación dinámica constituye el germen de lo que proponemos llamar el "giro estético-dramático cristiano".

\section{Mirar adentro. La via pulchritudinis como visión, valoración e interpretación de la figura estética}

En la acción de "ver, valorar e interpretar una figura" se halla expresado el legado estético teológico de Hans Urs von Balthasar, quien postuló la mirada sintética de retorno al centro para la cual el fragmento es manifestación de la totalidad. Esta perspectiva estética, que postula la percepción de la totalidad en la fragmentariedad de la figura, sólo es posible allí donde el absoluto se

\footnotetext{
${ }^{1}$ HANS URS VON BALTHASAR, "Aquello que debo a Goethe”, en ALBERTO ESPEZEL, Hans Urs von Balthasar. El drama del amor divino, Buenos Aires, Almagesto, 1993, 70.
} 
hace acción histórica, es decir, en la persona de Cristo: de ahí el carácter dramático de la expresión "el todo en el fragmento sólo porque el todo como fragmento", ${ }^{2}$ un fragmento que además se le presenta al hombre herido y partido. Esta figura (dimensión estética) no se cierra en un subjetivismo esteticista, sino que se abre a la acción (dimensión ético-dramática) y, en la acción, a la verdad (dimensión lógica). La figura se vuelve creíble aparece como una totalidad epifánica compuesta por tres elementos: primero, el fundamento que constituye la profundidad o contenido que se manifiesta; segundo, la forma en la que el fundamento aparece y fuera de la cual no hay manifestación posible; tercero, la luz o esplendor que es el resultado de la irradiación del proceso de la manifestación del objeto, en cuyo desinterés radica la inherente condición gratuita de lo bello. En la inmediatez de la manifestación de lo infundamentado del fundamento que aparece en la forma fundamentada tiene su origen la condición indomable de lo bello. "Misterioso trasfondo del ser que se transparenta en la apariencia", revelación del "exceso de ser" cuya irradiación se proyecta y derrama fuera de sí, "eterno cada vez más" que aparece en la finitud de una forma: son todas aproximaciones al fenómeno inagotable de lo bello.

El reconocimiento de la manifestación del abismo sin fondo en lo concreto y particular del fragmento constituye, para Balthasar, la fuente de la "alegría insondable" que da origen a atracción estética que se opera en el sujeto. ${ }^{3} \mathrm{De}$ aquí se sigue la exigencia subjetiva de mirar adentro hacia el centro epifánico objetivo, precisamente allí donde tiene lugar la gestación del hábito estético que, por ser respuesta a la figura objetiva no se cierra sobre sí, sino que busca su consumación más allá de sí en un libre asentimiento que compromete a la totalidad de lo humano. Se trata de la mirada estético-dramática, que el autor distingue tanto de la mirada crítica de Kant como de la mirada analítica de las ciencias naturales. En este horizonte hay que ponderar el lugar preeminente que la visión tiene en la estética de Balthasar. En efecto, "Schau der Gestalt" (visión de la figura) es el título del primer tomo de Gloria, la primera parte de su Trilogía dedicada a la estética teológica. ¿Se trata de la visión del ojo exterior

\footnotetext{
${ }^{2}$ HANS URS VON BALTHASAR, El todo en el fragmento, Madrid, Encuentro, 2008, 246. Cf. AVENATTI DE PALUMBO, CECILIA INÉS, "El todo en el fragmento: belleza y palabra como acontecimientos", en XX' Encuentro Nacional de Fenomenología y Hermenéutica. "Temporalidad, acontecimiento y destino", Academia Nacional de Ciencias de Buenos Aires, 1-4 de septiembre de 2009. Publicación en: Revista Franciscanum 157 (2012) (en prensa).

${ }^{3}$ Cf. HANS URS VON BALTHASAR, Teológica 1, Verdad del mundo, Madrid, Encuentro, 1997, 216-217.
} 
o del ojo interior? ¿Dónde acontece la aparición de lo sagrado, la teofanía, en el ámbito corporal, en el intelectual, o en el mundus imaginalis intermedio? De acuerdo con las representaciones del arte y pensamiento cristiano antiguo y medieval, a cuya tradición Balthasar se acoge, la mirada interior de la fe posee un potencial infinitamente superior al del mundo exterior pero también al del universo meramente intelectual. ${ }^{4}$ Sólo esta mirada interior alcanza a ver el centro donde está Dios, por eso los sentidos espirituales o interiores adquieren importancia decisiva en el proceso de percepción de la figura ${ }^{5}$. Pues bien, a la evidencia subjetiva que se realiza en el intersticio de los sentidos espirituales, le corresponde la evidencia objetiva de la figura que irradia desde sí la luz que la valida como tal. Este tipo de evidencia que no es el de la racionalidad sino el de la presencia. Por ello, dice el autor que:

Es conveniente definir con precisión qué entendemos por evidencia objetiva. Ha de ser una evidencia que salte a la vista y brille a partir del fenómeno mismo, no una evidencia que responda simplemente a necesidades del sujeto. La forma que históricamente viene a nuestro encuentro es en sí misma convincente, pues la luz que la hace brillar irradia desde sí misma y se muestra de un modo evidente como luz que emana de la cosa. ${ }^{6}$

En continuidad con la tradición agustiniana, también para la estética teológica de Balthasar el fundamento último de la interioridad del sujeto humano es el Dios que habita en la morada profunda del alma. Para el creyente que ama, la huella que su paso allí ha dejado grabada no es sólo una cuestión de gnosis, sino aguijón y nostalgia de presencia en la ausencia que atrae y opera una acción. Por ello, la contemplación cristiana del Dios encarnado, quien en figura de belleza vive en el interior del hombre, no puede ser asimilada sin más ni a la contemplación (theoréo) de las ideas eternas de los antiguos griegos, ni a la teoría de los modernos cuya índole abstracta es resultado de la aplicación de la razón universal y del método científico. Para referirse a la clase de contemplación activa que la revelación de Dios exige, Balthasar encuentra más apropiado el sentido del verbo theáomai con el que los griegos designaban la expectación teatral y la consecuente exigencia de participación del público en

\footnotetext{
${ }^{4}$ VICTORIA CIRLOT, La visión abierta, Barcelona, Siruela, 2010, 21, 22, 24.

${ }^{5}$ Cf. HANS URS VON BALTHASAR, Gloria. Una estética teológica 1. La percepción de la figura, Madrid, Encuentro, 1986, 323-375.

${ }^{6}$ Id. 416.
} 
el dejarse afectar y transformar por medio de la acción. La verdad cristiana es fundamentalmente dramática puesto que lo que hay en su centro no es ni una idea ni una moral sino la acción de Dios. Convertirla en pura teoría condujo al pensamiento cristiano a una desdramatización mortal que lo dejó atascado en los bancos de arena del racionalismo ${ }^{7}$. Por ello Balthasar introduce la analogia dramatis en el centro de su teología, presentando una original articulación entre la figura estética y lo teatral, entre la visión y la acción, ${ }^{8}$ cuestión a la que dedicaremos la segunda parte de esta exposición.

\section{Actuar desde el centro. La teodramática como consumación performativa de la teoestética}

Luego de analizar la evidencia objetiva de la figura como fundamento de la mirada estética, Balthasar propone considerar que la acción como contenido objetivo de la figura, estableciendo así un puente entre el ver y el actuar, entre la teoestética y la teodramática. Cuando como consecuencia de la acción, la figura sale de sí y provoca el arrebato en el sujeto, se está transitando el paso de la estética a la dramática. ${ }^{9}$ Sin embargo, el éxtasis estético constituye sólo el comienzo de la acción, por ello es necesario dar el paso a la confrontación entre la libertad infinita y la finita por medio de la determinación que los personajes actúan sobre el escenario del drama del mundo, cuya autoría y dirección está en las manos del Dios herido. Por ello, dice Balthasar que "la revelación de Dios no es ningún objeto para mirar, sino que es su propia acción en y para el mundo, la cual puede ser respondida, y así "comprendida" por el mundo mediante su acción"10. En la misma sintonía González de Cardedal señala que "las palabras solas, sean de Dios o del hombre, no tienen fuerza para transformar el mundo, si no van unidas con aquel poder interior que acompaña al sonido exterior". ${ }^{11}$ Este poder interior que brota de la figura es el poder de la acción. Por ello, el recurso a la metáfora del teatro como forma de revitalización del lenguaje de la fe tiene su fuente en la figura estética.

\footnotetext{
${ }^{7}$ Cf. HANS URS VON BALTHASAR, Teodramática 1. Prolegómenos, Madrid, Encuentro, 1990, 27. ${ }^{8}$ Cf. AVENATTI DE PALUMBO, CECILIA INÉS, La literatura en la estética de Hans Urs von Balthasar. Figura, drama y verdad, pról. Olegario González de Cardedal, Salamanca, Secretariado Trinitario, 2002, 299-334.

${ }^{9}$ HANS URS VON BALTHASAR, Teodramática 1. Prolegómenos, Madrid, Encuentro, 1990, 19. ${ }^{10}$ Id.

${ }^{11}$ OLEGARIO GONZÁLEZ DE CARDEDAL, La entraña del cristianismo, Salamanca, Secretariado Trinitario, 1998, 372.
} 
Al proponer una via pulchritudinis orientada hacia la acción teodramática, se logra un doble efecto: por un lado, se evitan los riesgos propios del esteticismo y de una ética de imperativos normativos; por otro lado, por medio del drama, se alcanza la superación de la dialéctica moderna entre la teoría y la práctica. De este modo, al concebir dramáticamente sus efectos perfomativos, la figura estética se determina en vistas a una acción en la que los elementos de la producción - autor, actor y director - se integran existencialmente con los elementos de la realización - representación, público y horizonte -. Esto significa que en la vía teodramática la acción se realiza sobre el escenario del mundo, en el horizonte de sentido de la obra divina y ante un público que participa activamente como comunidad cultural e históricamente llamada a co-realizar la representación de la obra del mundo. ${ }^{12}$

El teatro es una metáfora existencial en la que se pone en evidencia que el modo humano de conocer no se consuma en el ver sino en el actuar. En el teatro el decir y el hacer constituyen una figura unitaria. También en la teología teodramática de Balthasar para la cual la revelación no es sólo una comunicación informativa de verdades sobre Dios, sino de modo preeminente la auto-comunicación de Dios en actos y palabras. Dios es quien toma la iniciativa de revelar su obra de amor levantando él mismo mediante su acción el telón del teodrama. ${ }^{13}$ Para expresar la riqueza de esta realidad Balthasar introduce la noción de Tatwort, palabra-acción, justamente en el extenso capítulo dedicado a la hermenéutica teodramática de la Escritura. ${ }^{14}$

En efecto, la Palabra de Dios es operante, realiza lo que dice. El cristianismo es una religión profética por eso el teatro del mundo comienza con el llamado de

${ }^{12}$ Balthasar dedica la presentación del instrumental dramático a la segunda parte del primer tomo de su obra, la cual subdivide a su vez en dos partes dedicadas la primera al estudio histórico del topos del teatro del mundo y la segunda al análisis de los elementos de lo dramático. Cf. HANS URS VON BALTHASAR, Teodramática 1. Prolegómenos, Madrid, Encuentro, 1990, 129-461. A la investigación de la analogia dramatis en Balthasar hemos dedicado varios estudios que se encuentran reunidos en: CECILIA INÉS AVENATTI DE PALUMBO, "II. Parte Figuras en clave dramática. A. La vía teodramática como pathos epocal”, en Lenguajes de Dios para el siglo XXI. Estética, teatro y literatura como imaginarios teológicos, Juiz de Fora, Ediçoes Subiaco y Buenos Aires, Facultad de Teología UCA, 2007, 319-384.

${ }^{13}$ El planteo teodramático de Balthasar se encuentra en la base del "giro canónico-lingüístico" que propuso en su tesis un teólogo reformado, de cuya perspectiva de diálogo con la postmodernidad soy deudora en este artículo; sobre todo la introducción y las partes I y IV. Cf. VANHOOZER, KEVIN, El drama de la doctrina. Una perspectiva canónico-lingüística de la teología cristiana, Salamanca, Sígueme, 2010, 17-152; 443-538.

${ }^{14}$ Cf. HANS URS VON BALTHASAR, Teodramática 2. Las personas del drama: el hombre en Dios, Madrid, Encuentro, 1992, 85-138. 
Dios que acontece en el interior del hombre. Aquí se da el paso del mirar al oír, de la manifestación objetiva de la figura al llamado objetivo de la elección de Dios para ser en la vida un determinado personaje, el paso de la percepción estética a la acción teodramática. ${ }^{15}$ Así se refiere también O. González de Cardedal al dinamismo del llamado y respuesta en el contexto actual:

La percepción característica de la era moderna es que Dios llama al hombre desde dentro de sí, desde su más profundo centro y no desde fuera, dejándosele sentir como lo supremo necesario para ser hombre, fundar la libertad, asegurar la justicia y crear sentido. Dios suscita esta conciencia de necesidad e indigencia para darse al hombre como una inmensa riqueza y propuesta, pero a la vez le hace sentir su soberanía, transcendencia y santidad, como noche oscura, a fin de que lo descubra como Dios y no lo confunda con un mero instrumento a su servicio. La religión tiene que encontrar su senda entre una funcionalización de Dios, que lo convierte en pieza al servicio de su propia divinización, y una afirmación tal de su gratuidad trascendente, que lo deje ajeno a la existencia e insignificante para el destino humano. Dios es necesario en cuanto Dios y por ello gratuito. El cristianismo es un humanismo que surge del Hijo crucificado y resucitado, no de Adán y Prometeo autodivinizándose. [...] La palabra en el cristianismo no viene desde fuera sino desde dentro: Dios se revela desde el corazón de una persona. ${ }^{16}$

Ante la disolución postmoderna de la identidad, la llamada de Dios a representar el propio papel sobre el escenario del mundo significa la posibilidad de configurar al personaje no sobre las máscaras pasajeras de los imperativos culturales sino desde la mirada y la voz de un quién que nos mira y llama a configurar esa personalidad única que se define tanto por el origen de donde viene cuanto por el fin hacia donde va. Vista desde la perspectiva de la analogia dramatis, la llamada es iniciativa de Dios que nos ofrece un camino para pensar una respuesta ante la propuesta de determinación arbitraria de la identidad por la sociedad. Esta transformación del papel psicológico, social y cultural en misión otorgada por Dios a cada cual es el horizonte que inaugura la teodramática a partir de la introducción del topos del teatro del mundo como

\footnotetext{
${ }^{15}$ Cf. HANS URS VON BALTHASAR, "La llamada”, en Estados de la vida del cristiano, Madrid, Encuentro, 1994, 291-380.

${ }^{16}$ OLEGARIO GONZÁLEZ DE CARDEDAL, La entraña del cristianismo, Salamanca, Secretariado Trinitario, 1998, 350.
} 
analogia dramatis. Las categorías teológicas de elección, vocación y misión confirman y orientan el concepto de papel hacia la apertura de un nuevo camino que lleve a la cultura actual a plantearse la pregunta por el sentido de la existencia.

Pues bien, entre las posibilidades que ofrece la analogia dramatis al diálogo con la cultura postmoderna, resulta de gran interés la analogía entre el personaje y el creyente, dado que es justamente la identidad del sujeto la que pretende ser reducida a cenizas. En efecto, así sintetiza Vanhoozer el "manifiesto postmoderno":

El yo, ni autónomo ni soberano, se considera ahora codependiente y fragmentario, producto inestable de los múltiples códigos y convenciones que lo constituyen. 'El yo es multiplicidad, heterogeneidad, diferencia y constante hacerse, carente de origen y destino.' [...] Los postmodernos definen la identidad personal de modo social y no individual: un indicio de la raza, la etnia, el sexo, la cultura y la clase social. La pregunta “¿quién?" ha sido desplazada por otras más urgentes y políticamente densas, como “¿dónde?" o "¿en interés de quién?". El yo, nos dicen, depende de la situación sociopolítica. Con semejante trasfondo, la idea de que la persona tenga una naturaleza en lugar de un papel socialmente constituido -o de que los cristianos cuenten con un papel "propio" que desempeñar- se hace muy difícil de defender. ${ }^{17}$

Frente a este desafío, la vía teodramática propone afirmar la identidad personal y comunitaria en la trascendencia de "ser en Cristo". Para sostener esta posibilidad a partir de la analogia dramatis adoptada, Balthasar establece una correspondencia entre el método Stanislavski y el proceso de configuración de la personalidad cristiana. Tanto el papel teatral como la misión cristiana se construyen desde adentro, de modo tal que no se trata sólo de actuar, sino de convertirnos en los papeles que representamos, en una especie de encarnación de la personalidad por medio de un proceso de despojamiento de las falsas máscaras del yo. En ambos casos resulta decisiva la disponibilidad de la totalidad humana en la configuración del personaje dramático. Así se refiere Balthasar al aporte de Stanislavski a la teodramática:

${ }^{17}$ VANHOOZER, KEVIN, El drama de la doctrina. Una perspectiva canónico-lingüística de la teología cristiana, Salamanca, Sígueme, 2010, 444-445. 
$\mathrm{Su}$ método, en resumen, consiste en disponerse amplia y totalmente (cuerpo, alma espíritu) y en ponerse en movimiento hacia el papel que hay que asumir. disponibilidad de toda la estructura humana, comenzando por los ejercicios de relajación del cuerpo hasta los últimos miembros ("anatomizar") para tenerlos preparados para cada gesto, y continuando con los ejercicios de concentración que deben vencer la dispersión y semidistracción cotidiana, hasta la total activación de la imaginación primero en un objeto cualquiera, luego en una "situación propuesta" para concentrarse al final en el papel-; esta disponibilidad ensayada está orientada a encarnar de modo creíble la realidad poética del papel y a "justificar" su "verdad". El verdadero enemigo mortal contra el cual se lucha es el tradicional patrón teatral que permanece vacío como los conceptos sin intuiciones: un hablar y un gesticular pensado teóricamente, no creído y por tanto no creíble, que no puede legitimar internamente la acción sobre el escenario. De ningún modo es suficiente una "intuición sumaria"; si el actor también tiene que actuar dentro de la realidad del personaje que incorpora, ello presupone un grado supremo de conciencia y de capacidad técnica. [...] La disponibilidad no es evidentemente un esperar pasivo, sino que tiene como motor la fe en la verdad (del papel). [...] Dado que se está tratando de la personificación, hay que comenzar enseguida por lo corporal; hay que crear una "vida corporal" que es el "caldo de cultivo favorable para la creación del espíritu". El método de Stanislavski tiene algo de sacramental. ${ }^{18}$

Retornamos así al planteo inicial de mirar adentro y actuar desde el centro. La vía estético-dramática constituye un camino performativo que tiene derecho a ocupar su lugar en el escenario de nuestra cultura postmoderna que ha excluido al Dios cristiano de su horizonte. Esta inclusión se legitimaba ya en el punto de coincidencia entre lo teatral como categoría cósmica y existencial que atraviesa el ser, vivir y pensar del hombre abarcando la totalidad del drama divino-humano y la amplitud del concepto postmoderno de teatralidad como elemento configurador de la cultura actual a la que atraviesa en su totalidad. La postulación de un "giro estético-dramático cristiano" coincide con el rechazo postmoderno a la pretensión de universalidad absoluta del racionalismo. Pero, mientras la postmodernidad propone el reemplazo de la razón moderna por los tópicos del giro cultural lingüístico excluyendo también al sujeto y la

${ }^{18}$ HANS URS VON BALTHASAR, Teodramática 1. Prolegómenos, Madrid, Encuentro, 1990, 277-278. 
posibilidad de plantear la pregunta por la identidad personal y por el sentido de la existencia, la teodramática ofrece un camino de configuración de la identidad desde la mirada y la voz de Dios que actúa desde la otra orilla, convirtiendo el papel en misión e instalando en el seno de la existencia la tensión entre el quién de nuestra personalidad y el qué y el cómo del papel que representamos. Por ello, para Balthasar,

[...] en una teodramática no se trata ante todo de observar y juzgar, sino de participar en la representación y de la posibilidad de hacerlo. [...] En la medida en que un hombre se aproxima a esta identidad [papel-persona], con mayor perfección interpreta su papel; dicho de otro modo: los santos son los intérpretes auténticos del drama divino. Su sabiduría, vivenciada en su existencia dramática, debe ser considerada como normativa en la interpretación, no sólo para el drama vital de los individuos, sino en último término también para la «historia de la libertad» de los pueblos y de la humanidad en su conjunto. ${ }^{19}$

La identidad teodramática, que consiste "ser en Cristo", se realiza en la misión personal y única de cada hombre y mujer, con conciencia histórica del tiempo y del lugar que a cada uno le ha tocado en el reparto del teatro del mundo. El acto final no se ha consumado aún. Mientras tanto, el deber es responder actuando la propia misión personal y comunitaria, como lo hacen los santos. En el horizonte del complejo momento histórico que le toca transitar al diálogo entre cultura y cristianismo, haber encontrado en la vía estéticodramática puntos de encuentro desde donde poder pensar a Dios, al mundo y al hombre en sintonía con las búsquedas de nuestros contemporáneos no es poca cosa. Vivimos en el mismo desierto, representamos nuestros papeles sobre el mismo escenario vacío de Dios. De nuestro asentimiento depende que los papeles se conviertan en misiones, desde las cuales irradie la presencia del gran ausente, el inefable que se hizo Palabra y Acción.

\footnotetext{
${ }^{19}$ HANS URS VON BALTHASAR, Teodramática 2. Las personas del drama: el hombre en Dios, Madrid, Encuentro, 1992, 17.
} 


\section{Referências Bibliográficas}

AVENATTI DE PALUMBO, CECILIA INÉS, "El todo en el fragmento: belleza y palabra como acontecimientos", Franciscanum 157 (2012) 163-173.

_- La literatura en la estética de Hans Urs von Balthasar. Figura, drama y verdad, pról. Olegario González de Cardedal, Salamanca, Secretariado Trinitario, 2002.

—_ La vía teodramática como pathos epocal”, en Lenguajes de Dios para el siglo XXI. Estética, teatro y literatura como imaginarios teológicos, Juiz de Fora-Buenos Aires, Ediçoes Subiaco - Facultad de Teología UCA, 2007, 319-384.

BALTHASAR, HANS URS VON, "Aquello que debo a Goethe", en ALBERTO ESPEZEL, Hans Urs von Balthasar. El drama del amor divino, Buenos Aires, Almagesto, 1993.

__ El todo en el fragmento, Madrid, Encuentro, 2008.

_- Estados de la vida del cristiano, Madrid, Encuentro, 1994, Gloria. Una estética teológica 1. La percepción de la figura, Madrid, Encuentro, 1986.

——, Teodramática 1. Prolegómenos, Madrid, Encuentro, 1990.

_- Teodramática 2. Las personas del drama: el hombre en Dios, Madrid, Encuentro, 1992.

__, Teológica 1, Verdad del mundo, Madrid, Encuentro, 1997.

CERTEAU, MICHEL DE, La fábula mística: siglos XVI-XVII, México, Universidad Iberoamericana, [11982], 2004.

CIRLOT, VICTORIA La visión abierta, Barcelona, Siruela, 2010.

GONZÁLEZ DE CARDEDAL, OLEGARIO, La entraña del cristianismo, Salamanca, Secretariado Trinitario, 1998.

HAAS, ALOIS MARÍA, "Prinzip Theatralität bei Hans Urs von Balthasar", en KAPP-KIESEL-NIGGL (eds), Theodramatik und Theatralität. Ein Dialog mit dem Theaterverständnis bei Hans Urs von Balthasar, Berlin, Duncker \&Humboldt, 2000, 17-31. En castellano: "El principio de teatralidad en Hans Urs von Balthasar", AVENATTI DE PALUMBO, CECILIA, Lenguajes de Dios para el siglo XXI. Estética, teatro y 
literatura como imaginarios teológicos, Juiz de Fora, Ediçoes Subiaco y Buenos Aires, Facultad de Teología UCA, 2007, 464-482.

LEOCATA, FRANCISCO, Persona, lenguaje, realidad, Buenos Aires, Educa, 2003.

RODRÍGUEZ PANIZO, PEDRO, "Exploradores y cartógrafos. Teología de la experiencia mística cristiana", en VELASCO, JUAN MARTÍN (ed.), La experiencia mística. Estudio interdisciplinar, Madrid, Trotta, 2004.

VANHOOZER, KEVIN, El drama de la doctrina. Una perspectiva canónicolingüistica de la teología cristiana, Salamanca, Sígueme, 2010.

Cecilia Avenatti de Palumbo

Doctora en Letras por la Facultad de Filosofía y Letras

de la Pontificia Universidad Católica Argentina

Profesora Titular Ordinaria de Estética y Directora del Seminario de Investigácion (SIPLET)

Fundadora de Alalite con sede en Chile, Brasil y Argentina

E-mail: ceciliapalumbo@sion.com

Recebido em 15/03/2013

Aprovado em 13/06/2013 